\title{
A evolução dos mecanismos de proteção ambiental no Brasil e seu contexto
}

Samuel Alex Coelho Campos"

\section{Resumo}

Este trabalho objetiva apresentar a evolução dos mecanismos de proteção ambiental no Brasil por meio da revisão da literatura sobre o tema. A análise da literatura indicou que a preocupação com o meio ambiente no Brasil remete aos séculos XIV e XVIII, sendo influenciada pela visão utilitarista do meio ambiente. Durante a colonização e ao longo da história brasileira, a terra e os recursos naturais foram considerados inesgotáveis e utilizados no processo produtivo. A legislação acerca do meio ambiente é influenciada pelas pressões internacionais, que têm aumentado em função do aquecimento global, das emissões de gases do efeito estufa e do desmatamento. Contudo, a política ambiental brasileira carece de ações de educação ambiental para a população, além de recursos para fiscalização e repressão à degradação ambiental como a poluição e o desmatamento.

Palavras-chave: Política. Meio ambiente. Crescimento.

* Doutor em Economia Aplicada (Universidade de São Paulo/Escola Superior de Agricultura "Luiz de Queiroz). Professor Adjunto da Universidade Federal Fluminense, no Departamento de Ciências Econômicas de Campos. E-mail: samuelcampos@id.uff.br 


\section{Introdução}

A literatura que trata do meio ambiente tem atribuído o aumento das preocupações ambientais a partir da década de 1970, quando foi comemorado o primeiro Dia da Terra. Atualmente, a questão ambiental tem se concentrado no "desenvolvimento sustentável”. O aquecimento global tem sido foco de grande interesse, bem como as mudanças no Código Florestal, tanto internacional como nacionalmente.

Para Franzen e Meyer (2010), as preocupações quanto ao estado do planeta têm aumentado desde a publicação do relatório The Limits of Growth. Também merece destaque o relatório Our Common Future. Entretanto, a preocupação com o meio ambiente remete a um período anterior. Entre os séculos XIV e XVIII, período no qual as pessoas viviam somente dos frutos da terra, a maior atenção estava associada às flutuações do clima e aos seus efeitos sobre a colheita e a criação de animais, como os efeitos da "pequena era glacial" no reinado de Luís XIV (BRAUDEL, 2005).

Com o desenvolvimento econômico, as teorias que tratam da questão ambiental têm tentado retratar ou captar os motivos que conduzem à preocupação, à preservação e à conservação do meio ambiente. Isso pode estar associado: à presença de problemas ambientais locais, como poluição do ar, água, solo, etc. (FRANZEN; MEYER, 2010); às mudanças de valores, com o aumento da riqueza material, a criação de novas demandas e a valorização de outros valores, como liberdade política, proteção do meio ambiente, etc., o que é considerado como pós-materialismo, por Inglehart (1995); a um fenômeno global, em que a preocupação ambiental não seria influenciada pela riqueza de um país, de acordo com o novo paradigma ecológico (DUNLAP; MERTIG, 1995), ou pela prosperidade da nação, que assume que a qualidade ambiental é um bem que tem sua demanda positivamente relacionada à elevação da renda (DIEKMANN; FRANZEN, 1999).

Esses fatores podem caracterizar e guiar os mecanismos ambientais, no entanto, deve-se adicionar que a questão ambiental pode ser resultado da conveniência ou pressão externa à sociedade, como tem acontecido com a política ambiental brasileira em alguns períodos, de forma que o "desmazelo" para com o meio ambiente não resulte em barreiras à exportação. Ademais, a sociedade é formada por interesses heterogêneos, que podem ser, inclusive, antagônicos. As formulações e ações políticas estão relacionadas aos interesses desses diferentes grupos da sociedade (PECCATIELLO, 2011). 
Como forma de preservar o meio ambiente, o controle da poluição pode ser feito por meio de diversos tipos de políticas: comando-controle; usuário-pagador; poluidor-pagador; protetor-recebedor. Cada tipo de política apresenta um interesse e formas de ação específicos. Políticas do tipo protetor-recebedor, por exemplo, adotam incentivos, agregando retorno econômico aos "protetores" do meio ambiente (HUPFFER; WEYERMÜLLER; WACLAWOVSKY, 2011).

Dessa forma, a preocupação ambiental nacional será analisada na próxima seção, desde o descobrimento e a formação econômica do Brasil, na forma de colônia portuguesa, até os dias atuais, utilizando, para tal, a revisão de literatura acerca da temática. Objetiva-se interpretar e inserir as políticas nacionais de proteção e conservação do meio ambiente no contexto histórico, econômico e político presente em cada época.

\section{A evolução da proteção do meio ambiente}

A preocupação quanto à degradação ambiental no Brasil data de um período anterior ao século XX. As reflexões ambientais estavam presentes no país desde o século XVIII, segundo Pádua (2002). Ao contrário do que muito se tem pensado, a destruição do meio ambiente não era tida como uma consequência necessária do desenvolvimento, mas como um atraso ou desperdício, que deveria ser combatido por meio da modernização da agricultura brasileira. Essa crítica ambiental também era utilizada como argumentação contra o colonialismo e o escravismo, segundo Pádua (2002).

A colonização do Brasil tomou o caráter de empresa comercial, explorando os recursos naturais do país para o comércio europeu (PRADO JÚNIOR, 1983). Entretanto, a "proteção" do meio ambiente está presente desde o início da colonização, apresentando caráter utilitarista e político, conforme destacou Pádua (2002). O controle do meio ambiente era feito por meio de cartas régias, alvarás e provisões.

Esse caráter utilitarista era uma "herança" da política ambiental presente em Portugal no período das Grandes Navegações. As Ordenações Manuelinas (Rei Manuel Primeiro, 1469-1521) proibiam o corte de árvores frutíferas em Portugal e em suas colônias (NARLOCH, 2009). Na extração do pau-brasil, esse caráter estava presente, exemplo disso foi a outorgada Thomé de Souza em 1548, para a extração do pau-brasil, que deveria ser feita com o menor prejuízo da terra. 
A primeira lei de proteção florestal brasileira foi o Regimento do Pau-Brasil (1605), que, segundo Siqueira (2004), foi uma resposta aos conflitos pelo corte do pau-brasil. Essa lei regulou a extração do pau-brasil, proibindo sua extração sem expressa licença real. Esse regimento estabeleceu punições para a extração ilegal, sendo que os culpados poderiam ser, inclusive, condenados à morte. Essa legislação também estabeleceu normas para a extração da madeira: tudo deveria ser aproveitado e matas de pau-brasil não poderiam ser transformadas em roças. Segundo Narloch (2009), essa política garantiu a exploração sustentável das florestas até 1875 .

Contudo, a extração dessa madeira não seria suficiente para manter o "direito" português sobre as terras brasileiras. A colonização seria uma forma mais segura e barata. A abundância de terras criou um sistema de exploração extensivo e descuidado, que esgotava os recursos naturais, utilizando as terras até seu esgotamento (PRADO JÚNIOR, 1983). Esgotada a capacidade produtiva de uma área, novas áreas eram abertas pelo fogo, inicialmente as culturas se desenvolviam rapidamente, aproveitando-se do solo fértil e das cinzas (PÁDUA, 2002). Dessa forma, a produção agropecuária baseou-se na abundância dos recursos naturais, principalmente a terra. Ademais, a legislação também buscava incentivar a ocupação do território, como a legislação mineral, as Ordenações Manuelinas e, posteriormente, as Ordenações Filipinas, segundo Sánchez (2003).

Nos primeiros séculos da colonização, os efeitos negativos dessas práticas sobre o capital natural não foram percebidos, principalmente pelas grandes extensões a serem ocupadas. Entretanto, já no final século XVIII, esse caráter depreciador começa a ser sentido, mas faltavam conhecimentos científicos quanto ao sistema de produção adequado às características edafoclimáticas dos trópicos; o esgotamento passa a ser percebido, mas não há conhecimento que indique como proceder (PRADO JÚNIOR, 1983).

Esse sistema de exploração extensivo e descuidado, que esgotava os recursos naturais, criou momentos de prosperidade e decadência para as atividades produtivas agrícolas e extrativas, como o pau-brasil, a cana-de-açúcar, o algodão e a borracha (PRADO JÚNIOR, 1983). Nesse sistema de produção, a capitalização e o aumento de capacidade produtivo eram decorrentes da incorporação de mão de obra, principalmente escrava, e dos recursos naturais, com desflorestamento, extensas plantações, abertura de estradas, aumento dos rebanhos e edificação rural (FURTADO, 1968).

Posteriormente, a descoberta de metais preciosos, como ouro e diamantes, segundo Sánchez (2003), contribuiu para o assoreamento dos rios, com perfis 
desordenados e erosão do solo. $\mathrm{O}$ autor atribui a degradação ambiental à atividade mineradora como agente principal, atribuindo à agricultura e à pecuária menor responsabilidade.

A preocupação ambiental se faz presente também no período pós-independência. José Bonifácio defendeu que a agricultura baseada no trabalho e cravo e atrasada tecnologicamente transformaria as terras em desertos, bem como o jurista cearense Tomás Pompeu de Sousa (1860) (ZULAUF, 2000; PÁDUA, 2010). No período imperial, um dos maiores símbolos da preocupação ambiental, segundo Nazo e Mukai (2003), foi a recuperação da Floresta da Tijuca.

Com a proclamação da República em 1889, a Assembleia Nacional Constituinte inseriu na Constituição federal um capítulo sobre o meio ambiente. Nesse período, a destruição da natureza é criticada por razões políticas e pela perda da capacidade de aproveitamento produtivo desses recursos naturais (ZULAUF, 2000; PÁDUA, 2010).

Na Constituição Republicana Brasileira de 1891, apenas um artigo ( $n^{\circ} 34$, inciso 29) estava relacionado à questão ambiental, atribuindo à União a competência para legislar sobre minas e terras. O Código Civil de 1916 concedia o direito de embargo de obras que prejudicassem os vizinhos, considerando os aspectos ambientais (NAZO; MUKAI, 2003).

Consoante a isso, o país foi construído com a apropriação de terras, tendo na conquista espacial um forte elemento de identidade e coesão sociais. Um padrão de ocupação intensivo do ponto de vista dos recursos e extensivo no que tange ao espaço domina genericamente o histórico nacional, atribuindo-lhe um sentido expansionista "civilizador". Durante a era republicana, a modernização é perseguida, incluindo Vargas, JK e os governos militares, compreendendo o período de 1930 a 1985. O objetivo da ação foi o território, confundindo-o com o próprio país. Estradas deveriam ser construídas. Os recursos naturais eram vistos como uma riqueza a ser utilizada no processo produtivo, em que os recursos naturais e o espaço são considerados como inesgotáveis (MORAES, 2003).

Inicialmente, nesse período, incentivando a industrialização, o governo assumiu a responsabilidade de fornecer infraestrutura, racionalizando o uso dos recursos naturais (MONOSOWSKI, 1989). É nesse cenário que foram criados o Código das Águas, o Florestal (1934 e 1965), da Mineração, da Pesca, o Estatuto da Terra, a Lei de Proteção do Patrimônio Histórico e as agências setoriais. 
Segundo Peccatiello (2011), as regulações dos recursos naturais iniciaram a partir da década de 1930, com o objetivo de apropriação dos recursos naturais ao processo de industrialização. Essas políticas foram categorizadas por Monosowski (1989) como abordagens objetivando a administração dos recursos naturais, o controle da poluição industrial, o planejamento da ocupação territorial e a gestão dos recursos naturais de forma integrada. Ademais, segundo Garfield (2004), Vargas (1930-1945) aproveitou o nacionalismo geográfico para lançar a nação como de exuberância do mundo natural.

A Constituição de 1934 incorpora e expande os dispositivos relacionados às questões ambientais, estabelecendo a competência da União e dos estados na proteção das belezas naturais. O Decreto n⿳0 24.645/1934 estabeleceu a proteção dos animais, enquanto o Decreto no 24.643/1934 estabeleceu o Código das Águas, que incorporava a poluição das águas, a caça e a pesca (NAZO; MUKAI, 2003).

A primeira norma legal para regular o uso das águas, por meio do Decreto $\mathrm{n}^{0}$ 24.643/1934, disciplinou o aproveitamento industrial das águas e para a produção de energia elétrica de fonte hidráulica. Essa norma foi instituída em um ambiente "desenvolvimentista", em que os recursos naturais eram vistos apenas como "matéria-prima" barata e abundante para o desenvolvimento do país (CAMPOS; FRACALANZA, 2010). As principais ações, segundo esses autores, consistiam em aprovar as concessões, autorizar o uso da água, licenciar, fiscalizar e punir.

A poluição das águas passa a ser caracterizada como qualquer alteração das propriedades físicas, químicas e biológicas das águas que possa importar em prejuízo à saúde, à segurança e ao bem-estar das populações ou, ainda, comprometer sua utilização para fins agrícolas, industriais, comerciais e, principalmente, a existência normal da fauna aquática (BRASIL, 1934). Segundo Nazo e Mukai (2003), é nesse período que as regulamentações emergem, de forma mais concreta, com o intuito da conservação do meio ambiente.

No mesmo ano, foi instituído o primeiro Código Florestal do Brasil, por meio do Decreto no 23.793/1934, segundo o qual as florestas passam a figurar como de interesse de todos os cidadãos, instituindo também as Áreas de Preservação Permanente (APPs) (SIQUEIRA, 2004). Segundo Moraes (2003), a criação desses mecanismos conservacionistas seria consequência das redefinições dos sistemas produtivos dos países hegemônicos. Em 1943, é aprovado o primeiro Código de Caça, por meio do Decreto Lei no ${ }^{5}$.894/1943. 
Destacam-se, também, as criações da União Protetora do Ambiente Natural (Upan) em 1955, da Fundação Brasileira para a Conservação da Natureza (FBCN) em 1958, da Campanha pela Defesa e Desenvolvimento da Amazônia (CNNDA) em 1966 e da Associação Gaúcha de Proteção ao Ambiente Natural (AGAPAN) em 1971. Sendo que esta última era a mais ativa de todas, preocupada com diversas questões, como a poluição proveniente da aplicação excessiva de agrotóxicos na agricultura, formulava ações de promoção ecológica e denunciava os impactos predatórios da poluição causada pelas indústrias.

Em 1964, o Estatuto da Terra (Lei no 4.504) incluiu a conservação dos recursos naturais como uma das funções sociais da propriedade, condicionando, assim, as ações vinculadas aos direitos e às obrigações no uso da terra a essa prerrogativa. Em 1965, é feita a primeira reformulação do código de leis que regulamentava o setor florestal brasileiro (SIQUEIRA, 2004).

Todavia, podem ser feitas outras interpretações quanto às razões de criação desses mecanismos de proteção/conservação do meio ambiente. Para Siqueira (2004), o Código Florestal de 1965, com a criação do mecanismo de Reserva Legal, deu-se em razão do "ambientalismo desumano" predominante à época. O autor embasa sua argumentação no fato de que, na década de 1960, a área da Amazônia Legal desmatada correspondia a menos de $1 \%$ e, portanto, não haveria um padrão de desflorestamento a ser revertido ou contido.

Aspecto comumente criticado nos diversos códigos florestais é a ausência de estudos que analisem a perspectiva econômica e a quantidade socialmente desejada de desmatamento (SIQUEIRA, 2004; ARRAES; MARIANO; SIMONASSI, 2012). Ademais, a conservação de florestas envolve elevados custos de oportunidade decorrentes da privação de benefícios econômicos pelo comércio de madeira e da produção agropecuária, que, entretanto, são arcados exclusivamente pelos agricultores, mas que geram benefícios ambientais para toda a sociedade (FASIABEN et $a l .$, 2011; ARRAES MARIANO; SIMONASSI, 2012).

Com o Regime Militar (1964-1985), a preocupação ambiental assume tema de Primeiro Mundo. Apesar da emergência dos movimentos ecológicos internacionais, a relação com a natureza foi, em sua maioria, considerada como uma temática secundária perante a miséria, o analfabetismo, o desemprego, a falta de moradia e, principalmente, a ausência de democracia no Brasil (DUARTE, 2004). Esse período permitirá que as políticas apresentem caráter autoritário, o que, segundo Peccatiello (2011), perpetuará nas políticas públicas brasileiras. 
Nesse ambiente, "o governo militar brasileiro, por sua vez, rejeitou as propostas de conservação em Estocolmo (1972), em consonância com representantes de outros países pobres, como Indira Gandhi, que apontaram a pobreza como a pior poluição" (DUARTE, 2004, p. 145). Essa conferência foi realizada sobre o impacto da publicação do relatório The Limits of Growth, que propunha a desaceleração do desenvolvimento industrial nos países desenvolvidos (NASCIMENTO, 2012). Em 1973, foi criada a Secretaria Especial do Meio Ambiente (Sema), que não necessariamente seria reflexo de um comprometimento do governo militar com a questão ambiental, mas era uma estratégia do governo de atenuar sua imagem negativa no cenário externo devido à sua atuação na Conferência de Estocolmo, de forma a não sofrer restrições à exportação de produtos primários e obstruir o desenvolvimento do país (JACOBI, 2003; PECCATIELLO, 2011; NASCIMENTO, 2012). Assim, a política ambiental da década de 1960 era formulada de forma a responder às pressões ambientais internacionais.

Convém destacar que a Conferência de Estocolmo incorporou a dimensão social à questão ambiental, buscando atender tanto aos países desenvolvidos quanto aos em desenvolvimento. Assim, segundo Nascimento (2012), o problema ambiental passa a ser resultado do excesso das externalidades econômicas de desenvolvimento, bem como da falta desse.

A política ambiental dessa fase objetivou o combate da poluição, com propostas dominadas pela ótica tecnicista (MONOSOWSKI, 1989; MORAES, 2003). Predominou, ainda, a visão de que os recursos naturais deveriam ser utilizados para acelerar o processo de desenvolvimento econômico, desde que fossem considerados alguns cuidados, para minimizar os problemas ambientais advindos da poluição e preservar alguns recursos naturais (JACOBI, 2003).

Assim, embora a questão amazônica e o desmatamento fossem importantes fontes de preocupação, os primeiros estudos sistemáticos trataram da "agenda marrom". Foram as questões de qualidade ambiental urbana que motivaram os especialistas a ingressar nesse campo de estudos (HOGAN, 2001). A atenção inicial para a "agenda marrom" contrasta com o pensamento internacional, focado na perda de biodiversidade, no desmatamento e na degradação do solo. O foco na saúde e na distribuição da população refletia tanto a intenção de evitar uma visão simplista em relação à pressão sobre os recursos naturais, como a conviç̧ão de que, em um país urbanizado, o maior impacto sobre a população viria de questões ambientais urbanas (HOGAN, 2001). 
Segundo Jacobi (2003), a questão ambiental passou a ter maior expressão a partir da década de 1970, pelo retorno da democracia e pela pressão internacional. Há uma crescente pressão quanto ao desmatamento da Amazônia e à melhoria dos padrões de vida e renda. A partir desse período, a sociedade também passa a contestar os impactos ambientais provenientes da atividade mineradora e se mobiliza contra a degradação ambiental e sua poluição (SÁNCHEZ, 2003).

A Política Nacional do Meio Ambiente (PNMA) é promulgada (1981) em uma fase, segundo Monosowski (1989) e Moraes (2003), que priorizava ações de conservação e preservação de áreas pouco modificadas pela ação antrópica. Inúmeras unidades de conservação são criadas com uma visão "biologista". A PNMA disciplinou o Sistema Nacional do Meio Ambiente (Sisnama) e criou o Conselho Nacional do Meio Ambiente (Conama).

Com o retorno da democracia em 1985, a Constituição de 1988 incorpora o meio ambiente no Capítulo VI, artigo 225: "Todos têm direito ao meio ambiente ecologicamente equilibrado, bem de uso comum do povo e essencial à sadia qualidade de vida, impondo-se ao Poder Público e à coletividade o dever de defendê-lo e preservá-lo para as presentes e futuras gerações" (BRASIL, 2016, p. 131). Segundo Moraes (2003), essa nova Constituição caracteriza-se pelo guia teórico do "desenvolvimento sustentável", que pode ser percebido no artigo citado.

Ademais, a Constituição de 1988, com sua índole descentralizadora, induz o processo participativo na implementação das políticas públicas. Porém, esse modelo encontrará dificuldades de implantação no país, dada a tradição centralizadora e autoritária das políticas (MORAES, 2003). Ademais, conforme Campos e Fracalanza (2010), a promoção dessa articulação é benéfica, mas é necessário que existam incentivos para que os governos locais e a sociedade civil assumam maior responsabilidade no processo de implantação das políticas públicas.

No gerenciamento dos recursos hídricos, o marco legal nacional vigente é a Lei no 9.433/1997, que instituiu a Política Nacional de Recursos Hídricos. Essa política foi instituída em uma tentativa de integrar diversos agentes da sociedade interessados no gerenciamento dos recursos hídricos e gerir conflitos (CAMPOS; FRACALANZA, 2010). O modelo atual de gestão das águas no Brasil, segundo Campos e Fracalanza (2010), é resultado do esgotamento dos mecanismos de gestão baseados no "comando e controle". Na atividade mineradora, a Lei da Política Nacional do Meio Ambiente (1981), a Lei dos Interesses Difusos (1985) e a Constituição federal de 1988 expuseram os conflitos de interesses entre a sociedade e 
as empresas mineradoras com maior intensidade, com a sociedade se mobilizando contra impactos ambientais dessa atividade (SÁNCHEZ, 2003).

As últimas décadas do século XX e o início do século XXI têm sido marcadas pelos acordos internacionais de proteção do planeta, como a Convenção de Viena para a Proteção da Camada de Ozônio, em 1985; a Conferência da ONU sobre Meio Ambiente e Desenvolvimento, em 1992; o Protocolo de Quioto, em 1997; a Conferência das Partes de Marraqueche, em 2001; entre outras convenções. Entretanto, a implementação desses acordos internacionais, como o Protocolo de Quioto, por exemplo, encontra dificuldades, segundo Silva (2009), pelas divergências em relação ao ônus dos acordos e até mesmo pela dificuldade de consenso quanto à veracidade da participação da ação humana sobre o aquecimento global.

Esse período pode ser caracterizado como uma maior demanda por parte da sociedade por produtos ecologicamente corretos atribuída ao movimento do consumo consciente. Destacam-se nesse período episódios como a "Moratória da Soja", em 2006, que foi um compromisso da Associação Brasileira das Indústrias de Óleos Vegetais e da Associação Brasileira dos Exportadores de Cereais de não comercializarem e não financiarem a produção de soja proveniente de áreas que foram desmatadas no Bioma Amazônia após julho de 2006 (FABIANI, 2009). Presencia-se, também, o crescimento dos produtos certificados e selos, com destaque para os selos FSC, para produtos florestais; Ecocert, CMO, IMO, IBD e Control Union Certification, para produtos orgânicos; Rainforest Alliance Certified, para propriedades rurais e produtos agrícolas; Procel, eficiência enérgica de eletroeletrônicos; e Carbon Free, que certifica a compensação de emissões de carbono.

\section{Considerações finais}

A análise da legislação de preservação e conservação do meio ambiente brasileiro indicou a influência internacional sobre os mecanismos de proteção nacionais e a predominância do utilitarismo dado aos recursos naturais na concepção dessa legislação.

A dificuldade do país em valorizar o ambiente por si pode ser atribuída a diversos fatores, destacando-se a sua formação histórica, que objetivou a incorporação dos espaços e a imagem de abundância de recursos naturais. Entretanto, a legislação ambiental e os mecanismos de controle e preservação têm evoluído no Brasil, 
com a incorporação de incentivos como a criação dos protetores do meio ambiente por meio de políticas do tipo protetor-recebedor.

Ademais, com a retomada da democracia em 1986 e o caráter descentralizador da Constituição de 1988, a legislação ambiental começou a incentivar e a incorporar a comunidade local como importante agente de gestão e fiscalização, criando incentivos econômicos para isso, como a outorga pelo uso da água.

Contudo, há um caminho a ser percorrido quanto às políticas de preservação e conversação do meio ambiente, principalmente pela carência de parte da população por produtos básicos alimentares e pela baixa escolaridade média da população brasileira. Nesse cenário, o meio ambiente assume caráter secundário, enquanto as necessidades presentes de alimentação assumem maior importância para uma parcela da população que tem dificuldades de acesso à educação e à saúde. Acrescentam-se a esse cenário as crises fiscais e a redução dos recursos governamentais para ações de fiscalização e repressão à degradação ambiental, assim como movimentos políticos que não reconhecem e/ou questionam o avanço do desmatamento, por exemplo. Assim, é necessária uma mudança política, que privilegie a educação ambiental e que adote políticas robustas de repressão à degradação ambiental, à poluição e ao desmatamento, aplicando multas pesadas em caso de descumprimento da legislação ambiental. 


\title{
The evolution of environmental protection mechanisms in Brazil and its context
}

\begin{abstract}
This work aims to present the evolution of environmental protection mechanisms in Brazil through a review of the literature on the subject. The analysis of the literature indicated that the concern with the environment in Brazil goes back to the 14th and 18th centuries, being influenced by the utilitarian view of the environment. During colonization and throughout Brazilian history, land and natural resources were considered inexhaustible and used in the production process. Legislation about the environment is influenced by international pressures, which have increased due to global warming, greenhouse gas emissions and deforestation. However, the Brazilian environmental policy lacks environmental education actions for the population, in addition to resources for inspection and repression of environmental degradation such as pollution and deforestation.
\end{abstract}

Keywords: Politics. Environment. Growth.

\section{La evolución de los mecanismos de protección ambiental en Brasil y su contexto}

\section{Resumen}

Este trabajo tiene como objetivo presentar la evolución de los mecanismos de protección ambiental en Brasil mediante la revisión de la literatura sobre el tema. El análisis de la literatura indicó que la preocupación por el medio ambiente en Brasil se remonta a los siglos XIV y XVIII, influenciada por la visión utilitarista del medio ambiente. Durante la colonización y a lo largo de la historia brasileña, la tierra y los recursos naturales se consideraron inagotables y se utilizaron en el proceso de producción. La legislación sobre el medio ambiente está influenciada por las presiones internacionales, que han aumentado debido al calentamiento global, las emisiones de gases de efecto invernadero y la deforestación. Sin embargo, la política ambiental brasileña carece de acciones de educación ambiental para la población, además de recursos para la inspección y represión de la degradación ambiental, como la contaminación y la deforestación.

Palabras clave: Política. Medio ambiente. Crecimiento.

Classificação JEL: Q01, Q57, P28. 


\section{Referências}

ARRAES, R. D. A. E.; MARIANO, F. Z.; SIMONASSI, A. G. Causas do desmatamento no Brasil e seu ordenamento no contexto mundial. Revista de Economia e Sociologia Rural, v. 50, p. 119-140, 2012.

BRAUDEL, F. Civilização material, economia e capitalismo: séculos XV - XVIII. São Paulo: Martins Fontes, 2005.

BRASIL. Constituição (1988). Constituição da República Federativa do Brasil: com as alterações determinadas pelas Emendas Constitucionais de Revisão nos 1 a 6/94, pelas Emendas Constitucionais nos 1/92 a 91/2016 e pelo Decreto Legislativo no 186/2008. Brasília: Senado Federal, Coordenação de Edições Técnicas, 2016. 496 p.

BRASIL. Decreto no 24.643, de 10 de julho de 1934. Decreta o Código de Águas. Diário Oficial, Brasília, 20 jun. 1934. Seção 1, p. 14738.

CAMPOS, V. N. D. O.; FRACALANZA, A. P. Governança das águas no Brasil: conflitos pela apropriação da água e a busca da integração como consenso. Ambiente \& Sociedade, v. 13, p. 365-382, 2010.

DIEKMANN, A.; FRANZEN, A. The wealth of nations and environmental concern. Environment and Behavior, v. 31, n. 4, p. 540-549, July 1, 1999.

DUARTE, R. H. Por um pensamento ambiental histórico: O caso do Brasil. Luso-Brazilian Review, v. 41, n. 2, p. 144-161, December 1, 2004.

DUNLAP, R. E.; MERTIG, A. G. Global Concern for the Environment: Is Affluence a Prerequisite? Journal of Social Issues, v. 51, n. 4, p. 121-137, 1995.

FASIABEN, M. D. C. R. et al. Impacto econômico da reserva legal sobre diferentes tipos de unidades de produção agropecuária. Revista de Economia e Sociologia Rural, v. 49, p. 1051-1096, 2011.

FRANZEN, A.; MEYER, R. Environmental Attitudes in Cross-National Perspective: A Multilevel Analysis of the ISSP 1993 and 2000. European Sociological Review, v. 26, n. 2, p. 219-234, April 1, 2010.

FURTADO, C. Formação Econômica do Brasil. 8. ed. São Paulo: Companhia Editora Nacional, 1968.

GARFIELD, S. A Nationalist Environment: Indians, Nature, and the Construction of the Xingu National Park in Brazil. Luso-Brazilian Review, v. 41, n. 1, p. 139-167, June 1, 2004.

FABIANI, L. Relatório: $2^{\circ}$ ano de mapeamento e monitoriamento da soja no Bioma Amazônia. [S.l.]: Globalsat, 2009.

HOGAN, D. J. Demographic dynamics and environmental change in Brazil. Ambiente \& Sociedade, p. 43-73, 2001.

HUPFFER, H. M.; WEYERMÜLLER, A. R.; WACLAWOVSKY, W. G. Uma análise sistêmica do princípio do protetor -recebedor na institucionalização de programas de compensação por serviços ambientais. Ambiente \& Sociedade, v. 14, p. 95-114, 2011.

INGLEHART, R. Public Support for Environmental Protection: Objective Problems and Subjective Values in 43 Societies. Political Science and Politics, v. 28, n. 1, p. 57-72, 03/01, 1995. 
JACOBI, P. Movimento ambientalista no Brasil. Representação social ecomplexidade da articulação de práticas coletivas. In: RIBEIRO, W. C. (ed.). Patrimônio ambiental brasileiro. São Paulo: EDUSP, 2003. p. 519-543. (Uspiana: Brasil 500 anos).

MONOSOWSKI, E. Políticas ambientais e desenvolvimento no Brasil. Cadernos FUNDAP, v. 9, n. 16, 1989.

MORAES, A. C. R. Formação territorial e políticas ambientais no Brasil. In: RIBEIRO, W. C. (ed.). Patrimônio ambiental brasileiro. São Paulo: Editora da Universidade de São Paulo, 2003. Cap. 4. p. 79-87. (Estante USP: Brasil 500 Anos).

NARLOCH, L. Guia politicamente incorreto da história do Brasil. São Paulo: Leya, 2009.

NASCIMENTO, E. P. D. Trajetória da sustentabilidade: do ambiental ao social, do social ao econômico. Estudos Avançados, v. 26, p. 51-64, 2012.

NAZO, G. N.; MUKAI, T. O Direito Ambiental no Brasil: evolução histórica e a relevância do direito internacional do meio ambiente. In: RIBEIRO, W. C. (ed.). Patrimônio ambiental brasileiro. São Paulo: Editora da Universidade de São Paulo, 2003. Cap. 5. p. 91-124. (Estante USP: Brasil 500 Anos).

PECCATIELLO, A. F. O. Políticas públicas ambientais no Brasil: da administração dos recursos naturais (1930) à criação do Sistema Nacional de Unidades de Conservação (2000). Desenvolvimento e Meio Ambient, v. 24, 2011.

PRADO JÚNIOR, C. História econômica do Brasil. 29. ed. São Paulo: Brasiliense, 1983.

PÁDUA, J. A. Um sopro de destruição. Rio de Janeiro: Jorge Zahar, 2002.

PÁDUA, J. A. As bases teóricas da história ambiental. Estudos Avançados, v. 24, p. 81-101, 2010.

SILVA, D. H. D. Protocolos de Montreal e Kyoto: pontos em comum e diferenças fundamentais. Revista Brasileira de Política Internacional, v. 52, p. 155-172, 2009.

SIQUEIRA, C. F. A. Aspectos economicos da conservação de florestas em terras privadas: o Código Florestal e a Reserva Legal na Amazônia. 112 f. Dissertação (Mestrado em Ciências) - Departamento de Economia, Universidade de Brasília, Brasília, 2004.

SÁNCHEZ, L. E. A produção mineral brasileira: cinco séculos de impacto ambiental. In: RIBEIRO, W. C. (ed.). Patrimônio ambiental brasileiro. São Paulo: Editora da Universidade de São Paulo, 2003. Cap. 6. (Estante USP: Brasil 500 Anos).

ZULAUF, W. E. O meio ambiente e o futuro. Estudos Avançados, v. 14, p. 85-100, 2000. 